\title{
Prevalence and Pattern of Musculoskeletal Injuries among Recreational Weightlifters in Nnewi, Nigeria
}

\author{
Chidile Muonwe ${ }^{1,2}$, Samuel Chidiebere Nwobi ${ }^{1}$, Chiedozie James Alumona, ${ }^{3,4^{*}}$, \\ Chukwuebuka Okeke ${ }^{1}$, Chiamaka Ann Nwanne ${ }^{1}$, Ifeoma Blessing Nwosu', Ifeoma \\ Adaigwe Amaechi', Christian Arinze Okonkwo ${ }^{1}$, Ogochukwu Umeonwuka ${ }^{1}$, Ezinne \\ Chika Ekediegwu ${ }^{1}$, Uzoamaka Nwakaego Akobundu ${ }^{1}$ and Stanley M Maduagwu ${ }^{1}$
}

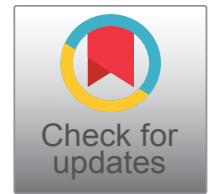

${ }^{1}$ Department of Medical Rehabilitation, Faculty of Health Sciences and Technology, College of Medicine, Nnamdi Azikiwe University, Awka, Nigeria

${ }^{2}$ Regions Comprehensive Rehabilitation Centre, Regions Stroke and Neuroscience Hospital, Mgbirich, Imo State, Nigeria ${ }^{3}$ Physiotherapy Department, College of Basic Medical Sciences, Chrisland University, Abeokuta, Nigeria

${ }^{4}$ Physiotherapy Department, College of Medicine, University of Ibadan, Ibadan, Nigeria

*Corresponding author: Chiedozie James Alumona, Department of Physiotherapy, College of Basic Medical Sciences, Chrisland University, Abeokuta, Nigeria, E-mail: chiedoziejames@yahoo.com

\begin{abstract}
Background: Weightlifters are prone to musculoskeletal injury. However, studies on the prevalence and pattern of musculoskeletal injuries among weightlifters in Nigeria are not available. Therefore, this study investigated the prevalence and pattern of musculoskeletal injury among recreational weightlifters in Nnewi, Nigeria and explored the association between the prevalence of injury and sociodemographic, and training characteristic variables.

Method: Ninety-one recreational weightlifters participated in this cross-sectional survey. An adapted, content-validated and pilot-tested self-administered questionnaire which captured information on participants' socio-demographics, training characteristics, injury prevalence and patterns during weightlifting in the past 6 months was used. Data were summarized using descriptive statistics and analyzed using Chi-square with alpha level at 0.05 .

Results: The prevalence of musculoskeletal injury was $47.3 \%$ and the most injured body part was the shoulder $(41.8 \%)$. There was significant association between the prevalence of injury and lack of supervision $(p=0.01)$, and between the prevalence of injury and training multiple times a day $(p=0.03)$.

Conclusion: Musculoskeletal injury is quite prevalent among recreational weightlifters with the shoulder being the most injured body parts. Training multiple times a day and lack of supervision were associated with the prevalence of injury.
\end{abstract}

\section{Keywords}

Prevalence, Pattern, Musculoskeletal injury, Weightlifters

\section{Introduction}

Weightlifting is a method of strength/resistance training in which a load is pulled or pushed as a form of resistance [1]. The load used are free weights (dumbbells, barbells, kettlebells) weight-selectorized machines, plate-loaded machines, and cable and pulley machines. Weightlifting is used as part of an exercise program or overall program to build muscle strength, muscle endurance and/or muscle hypertrophy [2] for effective injury prevention during other sports and has a very low injury incidence compared to other sports activities [3]. Other health benefits include increased resting metabolic rate, improved blood lipid profile, reduced resting blood pressure, improved bone mineral density, improved mental health, reduced risk for type 2 diabetes, decreased gastrointestinal transit time (reducing the risk of colon cancer), improved maximal aerobic capacity, reduced pain and discomfort for those suffering from osteoarthritis, decreased low back pain, and enhanced flexibility $[4,5]$. 
Despite these health benefits, weightlifting like other physical activities, predisposes weightlifters to musculoskeletal injury as it involves vigorous movements and use of equipment $[6,7]$. Kerr, et al. [8] reported that 25,335 weight training-related injuries were seen in United States (US) emergency departments from 1990-2007. The data collected showed an annual increase in recreational weightlifting injury across the years. Grier, et al. [9] reported a 12-month weight training injury prevalence of 4.5 and 0.6 for men and women respectively, among US Army Division. Hak, et al. [10] reported an injury rate of $73.5 \%$ sustained during routine CrossFit training (a blend of weightlifting with other functional exercise).

The anatomical areas at high risk of injury during weightlifting are low back, knee, upper back, shoulder, elbow, and wrist/hand in recreational weight lifting $[6,8]$. Majority of these injuries have been reported to occur in the upper limb (mostly in the shoulder) and low back $[8,11,12]$.

Despite these research works, there is dearth of literature on the prevalence and pattern of injury among weightlifters in Nigeria. It is important to understand the injury profile so as to reduce the negative effects and maximise the benefit of weight training. Therefore, this study was designed to investigate the prevalence and pattern of musculoskeletal injury among recreational weightlifters in Nnewi, Nigeria and to explore the association between the prevalence of injury and sociodemographic (gender, age and body mass index), and training characteristic (load, duration of participation, frequency of training per week, duration of training session, supervision and training multiple times a day) variables.

\section{Method}

\section{Participants}

Ninety-one (91) recreational weightlifters (aged 2059 years) participated in this cross-sectional survey. They were apparently healthy recreational weightlifters who were members of weightlifting centre or gym in Nnewi. This study excluded recreational weightlifters training independently away from a weightlifting centre or gym. The weightlifters were recruited through convenience sampling as those present on the day of data collection participated in the study.

A priori power analysis was performed using G*Power 3.1.9.7 software, based on alpha level of 0.05, power of 0.8 , effect size of 0.4 and degree of freedom of 5 . The minimum calculated sample size was 81 but 91 participants were recruited for the study. The study was hence sufficiently powered.

The study protocol was approved by the Ethical Committee of Nnamdi Azikiwe University Teaching Hospital, Nnewi. An approval was obtained from the management of the weightlifting centres or gyms. The participants were given a detailed explanation of the study protocol and its objectives. Those who volunteered to participate signed a written informed consent before being recruited for the study.

\section{Procedure}

Participants' body weight (in kilograms) and height (in meters) were measured using weighing scale and height meter, respectively and the body mass index (BMI) estimated using the formula.: $\mathrm{BMI}=$ Weight/ (height) ${ }^{2}$.

An adapted questionnaire that focused on injury prevalence and pattern in weightlifting in the past 6 months was self-administered to all the participants. The questionnaire was modified from a questionnaire developed by Mehrab, et al. [13] to evaluate injury incidence and patterns among Dutch CrossFit athletes. Content validity was done through review by a physiotherapist, a weightlifting coach and two recreational weightlifters. The questionnaire was modified based on the outcome of the review. It was pilot-tested at one of the weightlifting centres and changes made based on the feedback from the pilot participants. It is an 18-item questionnaire divided into three sections. The first section collects data on participants' socio-demographics, the second section collects data on training characteristics and the third section gathers information on prevalence and pattern of injury (Appendix 1).

Musculoskeletal injury was defined as any new musculoskeletal pain or feeling or discomfort that results from a weightlifting workout which makes the subject to adjust the duration, load or set/rep, discontinue an ongoing training session, skip training session(s) or contact a health professional in the past 6 months.

\section{Data analysis}

A post-hoc power analysis performed using $\mathrm{G}^{*}$ Power 3.1.9.7 software revealed that the study was sufficiently powered (0.85) at alpha level of 0.05 , sample size of 91 , effect size of 0.4 and degree of freedom of 5 . The data were analysed using SPSS 23.0 software (SPSS, Chicago, Illinois, USA). Descriptive statistics of mean, standard deviation, frequencies and percentages were used to summarize the data. Inferential statistics of Chisquare was used to explore the association between the prevalence of injury and socio-demographic, and training characteristic variables. The level of significance was set at 0.05 .

\section{Results}

Ninety-one (91) recreational weightlifters participated in this cross-sectional survey. Majority (91.2\%) of the participants were males and more than half (56\%) were $20-29$ years-old (Table 1 ). The mean height, weight and BMI are presented in Table 1. 
Table 1: Socio-demographics of participants.

\begin{tabular}{|c|c|c|c|c|}
\hline Variable & Class & Frequency (n) & Percentage (\%) & Mean \pm S.D \\
\hline Height (m) & & 91 & & $1.77 \pm 0.06$ \\
\hline Weight (kg) & & 91 & & $85.27 \pm 14.25$ \\
\hline BMI $\left(\mathrm{kg} / \mathrm{m}^{2}\right)$ & $\begin{array}{l}\text { Normal } \\
\text { Overweight } \\
\text { Obesity I } \\
\text { Obesity II } \\
\text { Obesity III }\end{array}$ & $\begin{array}{l}31 \\
42 \\
14 \\
3 \\
1\end{array}$ & $\begin{array}{l}34.1 \\
46.1 \\
15.4 \\
3.3 \\
1.1\end{array}$ & $26.93 \pm 4.10$ \\
\hline Gender & $\begin{array}{l}\text { Male } \\
\text { Female }\end{array}$ & $\begin{array}{l}83 \\
8\end{array}$ & $\begin{array}{l}91.2 \\
8.8\end{array}$ & \\
\hline Age & $\begin{array}{l}20-29 \\
30-39 \\
40-49 \\
50-59\end{array}$ & $\begin{array}{l}51 \\
35 \\
4 \\
1\end{array}$ & $\begin{array}{l}56 \\
38.5 \\
4.4 \\
1.1\end{array}$ & \\
\hline
\end{tabular}

Table 2: Training characteristics of participants.

\begin{tabular}{|c|c|c|c|}
\hline Variable & Class & $F(n)$ & $P(\%)$ \\
\hline Duration of participation & $\begin{array}{l}\geq 6 \text { months }<1 \text { year } \\
\geq 1<2 \text { years } \\
\geq 2<5 \text { years } \\
\geq 5 \text { years }\end{array}$ & $\begin{array}{l}13 \\
14 \\
52 \\
12\end{array}$ & $\begin{array}{l}14.3 \\
15.4 \\
57.1 \\
13.2\end{array}$ \\
\hline Training multiple times a day & $\begin{array}{l}\text { Yes } \\
\text { No }\end{array}$ & $\begin{array}{l}32 \\
59\end{array}$ & $\begin{array}{l}35.2 \\
64.8\end{array}$ \\
\hline Supervision & $\begin{array}{l}\text { Supervised } \\
\text { Unsupervised }\end{array}$ & $\begin{array}{l}36 \\
55\end{array}$ & $\begin{array}{l}39.6 \\
60.4\end{array}$ \\
\hline Duration of training session & $\begin{array}{l}\text { Less than } 30 \text { minutes } \\
30-59 \text { minutes } \\
60-89 \text { minutes } \\
90-119 \text { minutes } \\
120 \text { minutes and above }\end{array}$ & $\begin{array}{l}5 \\
14 \\
29 \\
21 \\
22\end{array}$ & $\begin{array}{l}5.5 \\
15.4 \\
31.9 \\
23.1 \\
24.2\end{array}$ \\
\hline Frequency of training per week & $\begin{array}{l}1 \text { day } \\
2 \text { days } \\
3 \text { days } \\
4 \text { days } \\
5 \text { days } \\
6 \text { days }\end{array}$ & $\begin{array}{l}4 \\
8 \\
19 \\
19 \\
17 \\
24\end{array}$ & $\begin{array}{l}4.4 \\
8.8 \\
20.9 \\
20.9 \\
18.7 \\
26.4\end{array}$ \\
\hline Rest days per week & $\begin{array}{l}1 \text { day } \\
2 \text { days } \\
3 \text { days } \\
4 \text { days } \\
5 \text { days } \\
6 \text { days }\end{array}$ & $\begin{array}{l}24 \\
19 \\
25 \\
14 \\
5 \\
4\end{array}$ & $\begin{array}{l}26.4 \\
20.9 \\
27.5 \\
15.4 \\
5.5 \\
4.4\end{array}$ \\
\hline
\end{tabular}




\begin{tabular}{|l|l|l|l|}
\hline Load & - $19 \mathrm{~kg}$ & 11 & 12.1 \\
& $20-39 \mathrm{~kg}$ & 23 & 25.3 \\
& $40-59 \mathrm{~kg}$ & 21 & 23.1 \\
& $60-79 \mathrm{~kg}$ & 27 & 29.7 \\
\hline Participation in other sports & $80 \mathrm{~kg}$ and above & 9 & 9.9 \\
& & 62 & 68.1 \\
\hline
\end{tabular}

$\mathrm{F}=$ Frequency $; \mathrm{P}=$ Percentage

Table 3: Prevalence and pattern of injury among participants.

\begin{tabular}{|c|c|c|c|}
\hline Variable & Class & $F(n)$ & $\mathbf{P}(\%)$ \\
\hline Injury & $\begin{array}{l}\text { Yes } \\
\text { No }\end{array}$ & $\begin{array}{l}43 \\
57\end{array}$ & $\begin{array}{l}47.3 \\
52.7\end{array}$ \\
\hline Reoccurrence of injury & $\begin{array}{l}\text { First time } \\
\text { Repeated }\end{array}$ & $\begin{array}{l}20 \\
23\end{array}$ & $\begin{array}{l}46.5 \\
53.5\end{array}$ \\
\hline Time of injury occurrence & $\begin{array}{l}\text { Early in the training } \\
\text { Middle in the training } \\
\text { Late in the training }\end{array}$ & $\begin{array}{l}9 \\
17 \\
17\end{array}$ & $\begin{array}{l}21.0 \\
39.5 \\
39.5\end{array}$ \\
\hline Part of the body injured & $\begin{array}{l}\text { Shoulder } \\
\text { Wrist } \\
\text { Hand } \\
\text { Biceps } \\
\text { Triceps } \\
\text { Elbow } \\
\text { Low back } \\
\text { Hamstrings } \\
\text { Quadriceps } \\
\text { Knee }\end{array}$ & $\begin{array}{l}18 \\
6 \\
5 \\
3 \\
1 \\
3 \\
3 \\
1 \\
1 \\
2\end{array}$ & $\begin{array}{l}41.8 \\
14.0 \\
11.6 \\
7.0 \\
2.3 \\
7.0 \\
7.0 \\
2.3 \\
2.3 \\
4.7\end{array}$ \\
\hline Type of injury & $\begin{array}{l}\text { Unsure } \\
\text { Strain/muscle tear } \\
\text { Sprain } \\
\text { Dislocation } \\
\text { General inflammation and pain }\end{array}$ & $\begin{array}{l}1 \\
6 \\
18 \\
6 \\
12\end{array}$ & $\begin{array}{l}2.3 \\
14.0 \\
41.8 \\
14.0 \\
27.9\end{array}$ \\
\hline
\end{tabular}

$\mathrm{F}=$ Frequency $; \mathrm{P}=$ Percentage

Table 4: Chi-square test showing the association between the prevalence of injury and some variables.

\begin{tabular}{|l|l|l|}
\hline Variable & $\mathbf{X}^{2}$ & $\boldsymbol{p}$-value \\
\hline Gender & 1.75 & 0.19 \\
\hline Age & 1.93 & 0.74 \\
\hline BMI & 1.95 & 0.74 \\
\hline Load & 8.00 & 0.16 \\
\hline Duration of participation & 4.46 & 0.34 \\
\hline Frequency of training per week & 6.73 & 0.24 \\
\hline Duration of training session & 2.73 & 0.60 \\
\hline Supervision & 10.53 & $0.01^{*}$ \\
\hline Training multiple times a day & 4.60 & $0.03^{*}$ \\
\hline
\end{tabular}

*statistically significant at $p<0.05$ level 
More than half $(60.4 \%)$ of the participants trained unsupervised, few (4.4\%) trained 1 day per week and the most session lasted from 60 to 89 minutes (31.9\%) (Table 2). More than half (57.1\%) of the participants had trained $\geq 2<5$ years and more than two-third $(68.1 \%)$ of the participants were involved in other sports (Table 2 ).

Almost half (47.3\%) of the participants had sustained musculoskeletal injury in the last 6 months with more than half $(53.5 \%)$ of them sustaining repeated injuries (Table 3). The most injured part of the body was the shoulder $(41.8 \%)$ and the most common type of injury was sprain (41.8\%) (Table 3). There was significant association between the prevalence of injury and lack of supervision $\left(X^{2}=10.53, p=0.01\right)$, and between the prevalence of injury and training multiple times a day $\left(\mathrm{X}^{2}\right.$ $=4.60, p=0.03$ ) (Table 4).

\section{Discussion}

The prevalence of musculoskeletal injury among recreational weightlifters in Nnewi was $47.3 \%$. This prevalence was higher than that reported by Grier, et al. [9]. They reported a 12-month weight training injury rate of 4.5 among US Army Division. The higher prevalence rate reported in the present study could be attributed to the fact that more than two-third (68.1\%) of the participants engaged in other sports apart from weightlifting. Thus, some of the injuries reported may not have resulted directly from weightlifting thereby leading to higher prevalence of musculoskeletal injury. Also, more than half $(60.4 \%)$ of them trained unsupervised. Thus, anyone who wants to weightlift is allowed to do so without prior testing and proper exercise planning which may have resulted in high injury rate.

Also, previous studies reported lower prevalence of injury (when compared to the rate reported in this study) among participants engaging in CrossFit. Weisenthal, et al. [7] and Tafuri, et al. [14] reported an injury rate of $19.4 \%$ and $39.9 \%$ among participants engaging in CrossFit in US and Italy, respectively, while Montalvo, et al. [15] reported a 6-month injury rate of 26.1 in South Florida. It is expected that the prevalence rate in the above studies will be higher than that reported in this study as CrossFit is a blend of multiple functional exercises such as gymnastics, Olympic lifting, power lifting and endurance exercises done at a high intensity [14]. However, the higher prevalence reported in this study can be attributed to the broad definition of injury in this study. Injury was defined "as any new musculoskeletal pain or feeling or discomfort that results from a weightlifting workout which makes the subject to adjust the duration, load or set/rep, discontinue an ongoing training session, skip training session(s) or contact a health professional" while the above studies in US and Italy defined injury as "any musculoskeletal pain or feeling or injury that results from CrossFit which leads to total removal from CrossFit training and other outside routine physical activities for $>1$ week, modification of normal training activities in duration, intensity, or mode for $>2$ weeks or any physical complaint severe enough to warrant a visit to a health professional." But Mehrab, et al. [13] reported a higher prevalence of $56.1 \%$ (when compared to the rate reported in this study) among participants engaging CrossFit in Netherlands probably because they considered a 12-month prevalence while a 6-month prevalence was considered in this study.

The commonly injured body parts in this study were the shoulder, wrist and hand. This is in accordance with previous studies that identified the upper $\operatorname{limb}$ as the body part most prone to injury $[8,16]$. The shoulder joint is the most injured body part in this study which is in consonance with previous studies $[7,10,13]$. The shoulder complex is predisposed to injury because of the repeated load it carries which turns it from a nonweight bearing joint to a weight bearing joint [17]. Also, weight training places emphasis on large muscle groups for strength and hypertrophy while neglecting muscles responsible for stabilization thereby creating imbalance between strength and mobility. Training routines that neglect either strength or mobility usually leads to injury $[16,18]$. Furthermore, the shoulder joint (glenohumeral) is the most mobile joint in the human body due to the loose joint capsule, and the relative size of the humeral head compared to the shallow glenoid fossa (4:1 ratio in surface area). The increased mobility of the joint predisposes it to injury [19].

More than half (53.5\%) of the injury prevalence were repeated injuries. This may indicate poor management of previous injuries sustained by participants as they may not have had adequate recovery time before going back to weightlifting or visited the appropriate health personnel to assist in the management of injury.

The most common reported type of injury is sprain. This could explain the reason shoulder, wrist and hand were the most injured parts of the body as sprain usually occurs in the joint ligaments [20]. Strain/muscle tear was among the least reported type of injury. This could probably be linked to the aim of weightlifting. Weightlifting focuses on strength and hypertrophy and not on flexibility as flexibility exercises usually leads to strain and muscle tear [21].

There was significant association between training multiple times a day and the prevalence of injury. Training multiple times a day leads to greater daily training exposure to weightlifting which has been identified as a risk factor for weight training injury $[9,15]$. Training multiple times a day without adequate rest may lead to fatigue which may ultimately results in deterioration of concentration and loss of skill thereby causing injury. Fatigue may explain the reason most of the reported injury in this study occurred during mid and late training session. 
Lack of supervision was significantly associated with the prevalence of injury. This is consistent with the report by Weisenthal, et al. [7] that those who exercise under supervision experience lower injury rate than those without supervision. Coaches or supervisors organize the class, aid in choosing the correct weight, guide through the workouts and provide feedback both during and after each exercise bouts. The continuous feedback can create awareness on proper form, technique, weight room etiquette, equipment handling as well as undesirable and potentially dangerous positions [22].

\section{Limitations}

First, we used a 6-month prevalence survey which may have introduced recall bias due to its retrospective nature. The participants might have completed the survey under a fatigued state which may have also influenced their ability to recall. This might have resulted to the overestimation or underestimation of the prevalence of injury. Also, there was no validation or diagnosis of the injuries by health professionals. This might have left space for personal interpretation of injury as we collected data directly from the recreational weightlifters. The definition of injury used in this study may have resulted in overestimation of the prevalence of injury. However, the strength of the definition lies in its broad coverage by taking into consideration the possible neglected injury. Future research should be prospective in nature to avoid recall bias and injuries should be validated by a health professional. Also, future research should expand the risk factors for injury in recreational weightlifting.

\section{Conclusion}

The 6-month prevalence of musculoskeletal injury among recreational weightlifters in Nnewi was $47.3 \%$. The commonly injured body parts were the shoulder, wrist and hand. Training multiple times a day and supervision were associated with the prevalence of injury. The findings of this study may provide insight for sports physiotherapists, coaches, recreational weightlifters and other health professionals about the injury profile in order to reduce the injury rate.

\section{Acknowledgment}

The authors would like to thank the managements of the weightlifting centres and the recreational weightlifters for approving and/or participating in this study. The authors declare no conflict of interest. The authors did not receive any external funding for the study.

\section{Sources of Support}

The authors did not receive any external funding for the study.

\section{Statement of Authors' Contribution}

All authors met the criteria for authorship.

\section{References}

1. Busche K (2008) Neurologic disorders associated with weight lifting and bodybuilding. Neurol Clin 26: 309-324.

2. Hurley SK, Flippin KJ, Blom LC, Bolin J, Hoover DL, et al. (2018) Practices, perceived benefit and barrier to resistance training in women enrolled in college. Int J Exerc Sci 11: 226-238.

3. Faigenbaum AD, Myer GD (2010) Resistance training among young athletes: safety, efficacy and injury prevention effects. Br J Sports Med 44: 56-63.

4. Wescott WL (2012) Resistance Training is Medicine: Effects of Strength Training on Health. Curr Sports Med Rep 11: 209-216.

5. Fisher J, Steele J, Bruce-low S, Dave S (2011) Evidencebased resistance training recommendations. Medicina Sportiva 15: 147-162.

6. Gray SE, Finch CF (2015) Epidemiology of HospitalTreated Injuries Sustained by Fitness Participants. Res Q Exerc Sport 86: 81-87.

7. Weisenthal BM, Beck CA, Maloney MD, Dehaven KE, Giordano BD (2014) Injury rate and patterns among CrossFit athletes. Ortho J Sports Med 2: 2325967114531177.

8. Kerr ZY, Collins CL, Comstock RD (2010) Epidemiology of weight training related injuries presenting to United States emergency departments, 1990-2007. Am J Sport Med 38: 765-771.

9. Grier T, Brook RD, Solomon Z, Jones BH (2020) Injury Risk Factors Associated with Weight Training. J Strength Cond Res.

10. Hak PT, Hodzovic E, Hickey B (2013) The nature and prevalence of injury during CrossFit trainings. J Strength Cond Res.

11. Fares MY, Fares J, Salhab HA, Khachfe HH, Bdeir A, et al. (2020) Low back pain among weightlifting adolescents and young adults. Cureus 12: 9127.

12. Kolber MJ, Beekhuizen KS, Cheng, MS, Hellman MA (2010) Shoulder injuries attributed to resistance training: A brief review. J Strength Cond Res 24: 1696-1704.

13. Mehrab M, De Vos RJ, Kraan GA, Mathijssen NMC (2017) Injury Incidence and Pattern among Dutch CrossFit athletes. Ortho J Sports Med 5: 2325967117745263.

14. Tafuri S, Salatino G, Napoletano Monno A, Notarnicola A (2018) The risk of injuries among CrossFit athletes: an Italian observational retrospective survey. J Sports Med Phys Fitness 59: 1544-1550.

15. Montalvo AM, Shaefer H, Rodriguez B, Li TM, Epnere K, et al. (2017) Retrospective epidemiology and risk factor of injury in CrossFit. J Sports Sci Med 16: 53-59.

16. Golshani K, Cinque ME, O'Halloran P, Softness K, Keeling L, et al. (2018) Upper extremity weightlifting injuries: Diagnosis and Management. J Orthop 15: 24-27.

17. Kolber MJ, Cheatham SW, Salamh PA, Hanney WJ (2014) Characteristics of shoulder impingement in the recreational weight training population. J Strength Cond Res 28: 10811089.

18. Cools AM, Declercq GA, Cambier DC, Mahieu NN, Witvrouw EE (2007) Trapezius activity and intramuscular balance during isokinetic exercise in overhead athletes with impingement symptoms. Scand J Med Sci Sports 17: 25-33.

19. Rugg CM, Hettrich, CM, Ortiz S, Wolf BR, MOON Shoulder 
Instability Group, Zhang AL (2018) Surgical stabilization for first-time shoulder dislocators: a multicenter analysis. J Shoulder Elbow Surg 27: 674-685.

20. Benjamin, HJ, Engel SC, Chudzik D (2017) Wrist Pain in Gymnasts: A Review of Common Overuse Wrist Pathology in the Gymnastics Athlete. Curr Sports Med Rep 16: 322329.
21. Storey A, Smith HK (2012) Unique aspects of competitive weightlifting: Performance, training and physiology. Sports Med 42: 769-790.

22. Myer GD, Quatman CE, Khoury J, Wall EJ, Hewett TE (2009) Youth versus adult "weightlifting" injuries presenting to United States emergency rooms: Accidental versus nonaccidental injury mechanisms. J Strength Cond Res 23: 2054-2060. 


\section{APPENDIX 1}

A Survey on participant's socio-demographics, training characteristics, prevalence and pattern of musculoskeletal injuries during recreational weightlifting in the last six months.

Section 1: Socio-demographics

1. What is your gender?

$$
\begin{aligned}
& \text { Male } \\
& \text { Female }
\end{aligned}
$$

2. What is your age?

$$
\begin{aligned}
& \square 20-29 \\
& \square 30-39 \\
& \square 40-49 \\
& \square 50-59 \\
& \square 60 \text { and above }
\end{aligned}
$$

3. Height

4. Weight

5. Body Mass Index

\section{Section 2: Training Characteristics}

6. How long have you been weightlifting?

$$
\begin{aligned}
& 6 \text { months to less than } 1 \text { year } \\
& 1 \text { year to less than } 2 \text { years } \\
& 2 \text { years to less than } 5 \text { years } \\
& 5 \text { years and above }
\end{aligned}
$$

7. Do you train multiple times a day?
$\checkmark$ Yes
$\square$ No

8. Do you weightlift with or without supervision?

$\square$ Supervised

$\square$ Unsupervised

9. On the average, how long do you train per session?
$\square$ Less than 30 minutes
30 minutes -59 minutes
$\square 60$ minutes -89 minutes
$\square 90$ minutes -119 minutes
$\square 120$ minutes and above

10. On the average, how many days do you train per week?
1 day
2 days
3 days
$\square$ days
$\square 5$ days 


\section{6 days \\ 7 days}

11. On the average, how many rest days do you take per week?

$$
\begin{aligned}
& \square 1 \text { day } \\
& \square 2 \text { days } \\
& \square 3 \text { days } \\
& \square 4 \text { days } \\
& \square 5 \text { days } \\
& \square 6 \text { days }
\end{aligned}
$$

12. What amount of weight do you lift during weightlifting?

$$
\begin{aligned}
& 0-19 \mathrm{~kg} \\
& 20 \mathrm{~kg}-39 \mathrm{~kg} \\
& 40 \mathrm{~kg}-59 \mathrm{~kg} \\
& 60 \mathrm{~kg}-79 \mathrm{~kg} \\
& 80 \mathrm{~kg} \text { and above }
\end{aligned}
$$

13. Do you participate in other sports aside weightlifting? If yes, what sports?

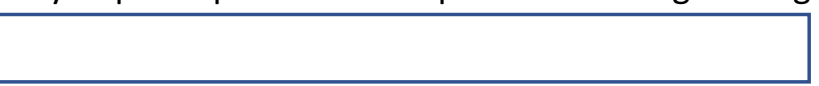

\section{Section 3: Injury}

14. Have you been injured while weightlifting in the past 6 months? This is explicitly about injuries you have sustained during weightlifting.

$$
\begin{aligned}
& \square \text { Yes } \\
& \square \text { No }
\end{aligned}
$$

NB: You have sustained injury if you have met at least one of the following criteria in the last 6 months:

- Modification of normal training activities in terms of duration, load or set/rep

- Discontinuation of an ongoing training session.

- Skip training session(s)

- Any physical complaint that made you contact a health professional.

If you answered YES, please move on to the next question. If NO, please discontinue and summit the questionnaire to the researcher.

15. Is this the first time you have sustained this injury or is it repeated?

$$
\begin{aligned}
& \text { First time } \\
& \text { Repeated }
\end{aligned}
$$

16. At what time in the training session did the injury occur?

Early in the training

Middle in the training

Late in the training

17. What part of your body was Injured?

Shoulder

$\square$ Wrist

$\square$ Hand 


$\square$ Neck
$\square$ Bicep
$\square$ Triceps
$\square$ Elbow
$\square$ Upper back
$\square$ Low back
$\square$ Groin
$\square$ Hamstring
$\square$ Quadriceps
$\square$ Knee
$\square$ Ankle
$\square$ Foot

18. What type of injury did you sustain?
$\square$ Unsure
$\square$ Strain/muscle tear
$\square$ Sprain
$\square$ Dislocation
$\square$ General inflammation and pain 